\title{
Magnetic Nanoparticles as a Redispersing Additive in Magnetorheological Fluid
}

\author{
M. Aguilera Portillo ${ }^{1}$ and G. R. Iglesias ${ }^{2}$ \\ ${ }^{1}$ La Salle University, Mexico City, Mexico \\ ${ }^{2}$ Department of Applied Physics, School of Science, University of Granada, 18071 Granada, Spain \\ Correspondence should be addressed to G. R. Iglesias; iglesias@ugr.es
}

Received 29 January 2017; Accepted 18 April 2017; Published 30 May 2017

Academic Editor: Zehra Durmus

Copyright ( 2017 M. Aguilera Portillo and G. R. Iglesias. This is an open access article distributed under the Creative Commons Attribution License, which permits unrestricted use, distribution, and reproduction in any medium, provided the original work is properly cited.

\begin{abstract}
Unwanted agglomeration of micro particles in magnetorheological fluid is an important problem for many technological applications. Furthermore, the stability of this kind of fluid is also studied as an important property in many research papers. Prior to use, a redispersion of agglomerated or aggregated (connected by solid phase) particles is often necessary. The objective of this study is to evaluate the dispersibility effect of magnetic nanoparticles as a carrier, while keeping the magnetorheological (MR) effect as high as possible. A simple device based on the estimation of the penetration force of a standard needle is presented. The needle moves across the sample vertically with a constant velocity and it is attached to a scale which registers the force displaced by the needle during the dynamic test. The effect with and without other additives was also studied. Transmission electron microscopy (TEM) and Scanning Electron Microscopy (SEM) reveal a protective behavior of nanoparticles around the micro particles. We conclude that addition of magnetic nanoparticles improves the dispersibility characteristic compared with common dispersing additives without affecting the MR effect.
\end{abstract}

\section{Introduction}

A magnetorheological fluid (MRF) is a smart soft material with a dramatic rheological magnetic field-response, which increases the apparent viscosity of the MRF suspension [1], proportional to the strength of the magnetic field [2] due to the high concentration of magnetizable micro size particles $[3,4]$, typically spherical [5], and suspended in a nonmagnetic carrier [6]. The characterization of this programmed response materials, the volume content of particles, size, and shape [7-9] determines its technological applications, among biomedical prosthesis, dampers and seismic insulators, aerospace industry, and drug vehicles design to mention just a few $[8,10-15]$.

One of the major problems concerning these suspensions and specifically in MRF applications is the stability and redispersibility of the fluid, which is one pending task to be considered. The sedimentation phase is an inevitable phenomenon, inherent to the density difference between the components of the MRF [16], highly dependent on the electrochemical repulsive forces, which results from the interaction between electrolytes adsorbed to the surface material of the suspended magnetizable particles, and the composition of the dispersing phase $[16,17]$. Both the gravitational physical phenomena, centrifugal acceleration and electromagnetism [18-20], and the electrochemical forces result in the accumulation of the solid phase, forming the so called cake, in the bottom of the container. Several efforts have been made in order to improve the stability in magnetorheological suspensions, like adding iron particles to polymeric matrixes [21,22].

The rheological behavior of a "well designed" MRF should have an easily and widely tunable response by the application of the magnetic field. The response is maximized for sufficiently high particle concentrations, and this may require solids contents as high as $30 \% \mathrm{v} / \mathrm{v}$. The typically use of organic media, surface modifier, or nonmagnetic nanoparticles [23-29] could improve the stability of the fluid but also have the disadvantages of the increased viscosity of the system and thus could hinder the magnetorheological effect. In some cases the organic media have no surface charge and hence 


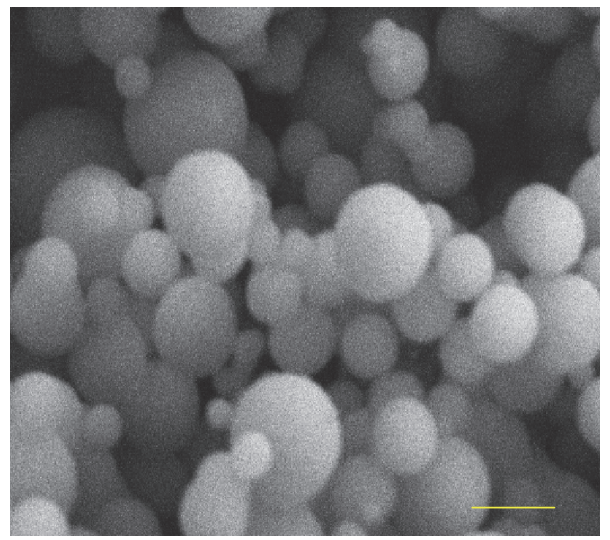

(a)

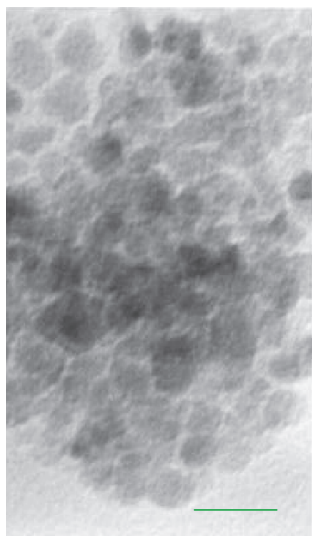

(b)

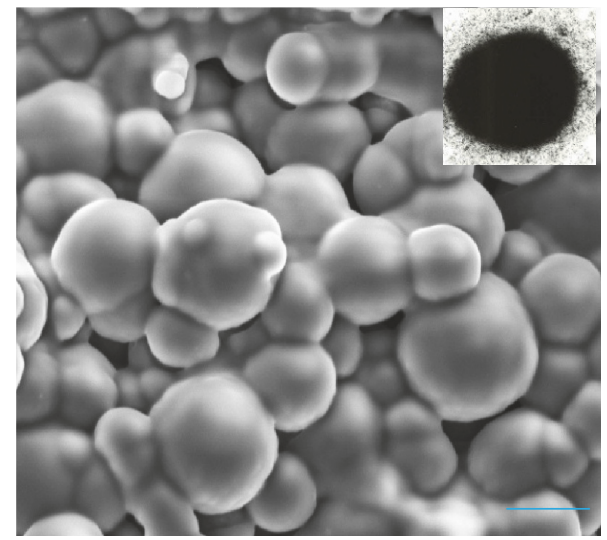

(c)

FIGURE 1: (a) SEM picture of the iron micro particles; bar length $5 \mu \mathrm{m}$. (b) TEM picture of the magnetite nanoparticles; bar length $20 \mathrm{~nm}$. (c) SEM picture of the iron micro particles and magnetite nanoparticles; bar length $5 \mu \mathrm{m}$ (inset picture: cloud of nanoparticles around one Fe micro particle).

there is no electrostatic repulsion between particles, which could prevent their irreversible aggregation induced by van der Waals and magnetic (due to the remnant magnetization) interactions.

Still nowadays how to evaluate this characteristic is not clear and a few researches were focusing on the stability of this suspension and not what happened after the sedimentations occurs. A good dispersibility is associated with ease and quickness of dispersion and poor dispersibility with difficulty and slowness of dispersion. This often is related to rates, and therefore the rate of dispersion with time is commonly held to be related to, or indeed to be, a measure of dispersibility or redispersibility.

Meanwhile, redispersion is one of the biggest challenges in the characterization of MRF $[30,31]$. It can be described as the capability of an MR suspension to incorporate homogeneously the sediment through the suspension, once the particles have settled, in which the most important thing to determine is the stiffness of the sediment [32]; the lower it is, the easier it is to redisperse by shaking [33].

Described by Bombard et al. [34], the measure of the redispersibility can be estimated by the calculation of the work applied from a penetrating steel blade onto an MRF at a constant speed of $1 \mathrm{~mm} / \mathrm{s}$. The calculation consisted in integrating the area under the curves of force as function of displacement. Some variations of this method previously described were presented later by Iglesias et al. [33] using a standard needle and the hardness of the sediment was recorded by digital weighing scale.

Later on, it is shown $[35,36]$ that, in order to achieve more redispersibility in an MRF, the ferromagnetic particles should be coated with a high-temperature fluorinated polymer which could be implemented. Furthermore [35] provides the measurement of the cake hardness, which is carried out by a micromechanical instrument DMA-7e, PerkinElmer, Waltham, MA.
In this work, the effects of three MRF samples with 30\% $\mathrm{v} / \mathrm{v}$ volume fraction of solid phase of magnetic micro particles in mineral oil dispersing in MR \#1: $0.4 \%$ AlSt (aluminum stearate), MR \#2: $0.4 \%$ AlSt (the viscosity modifier is a mixture of two polymers: one is a polyester (like 2-alcoxy-dialkylsuccinate) and the other is a styrene-di(alkyl) fumarate block copolymer), and MR \#3: 6.2\% v/v volume fraction nanoparticles as a carrier fluid (ferrofluid) without other additives were investigated by the penetration of a standard needle and a weight scale. The results show that the addition of nanoparticles could improve the dispersibility behavior of the MRF, keeping a highest value on the magnetorheological effect. Furthermore, the penetration technique can be a complementary test to predict the storage behavior in MRFs.

\section{Materials and Methods}

2.1. Materials. HQ carbonyl iron powder from BASF (Germany) was used as solid phase. It consists of polydisperse spherical particles with a median particle size of $d_{50}=2.3 \mu \mathrm{m}$ (particle diameter ranges from 0.5 to $3 \mu \mathrm{m}$ ) and an iron content of $97 \%$ (density $=7.5 \mathrm{~g} / \mathrm{cm}^{3}$ ). The base carrier fluid was mineral oil (Sigma Aldrich) and it was used for all the suspensions; its viscosity at $25^{\circ} \mathrm{C}$ is $(0.028 \pm 0.001) \mathrm{Pa}$.s. Samples MR \#1 and MR \#2 contain aluminum stearate (Aldrich), and MR \#2 has a viscosity modifier to improve the stability and it is composed of two polymers: one is a polyester (2alcoxy-dialkyl-succinate) and the other is a styrene-di(alkyl) fumarate block copolymer. MR \#3 contains nanoparticles (ferrofluid) used as carrier. It was prepared following the procedure described in [37], the nanoparticles have an average size of $7.8 \pm 0.3 \mathrm{~nm}$. The ferrofluid carrier had a solid concentration of $6.2 \%$ by volume. Figure 1 (a) shows the TEM picture of the iron micro particles while Figure 1(b) shows the SEM picture of the nanoparticles used. As we can see in Figure 1(c) 


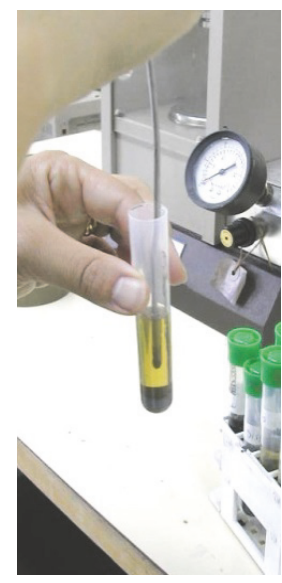

(a)

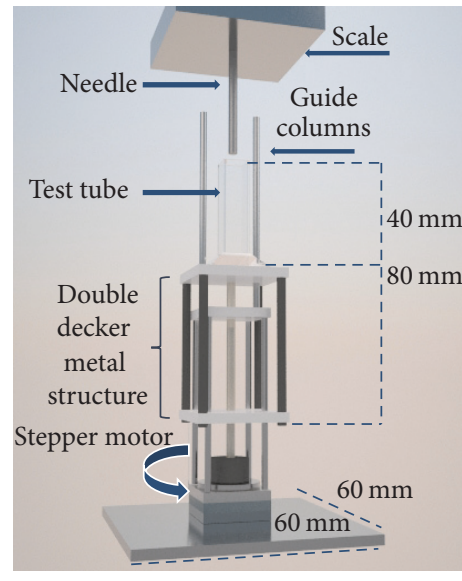

(b)

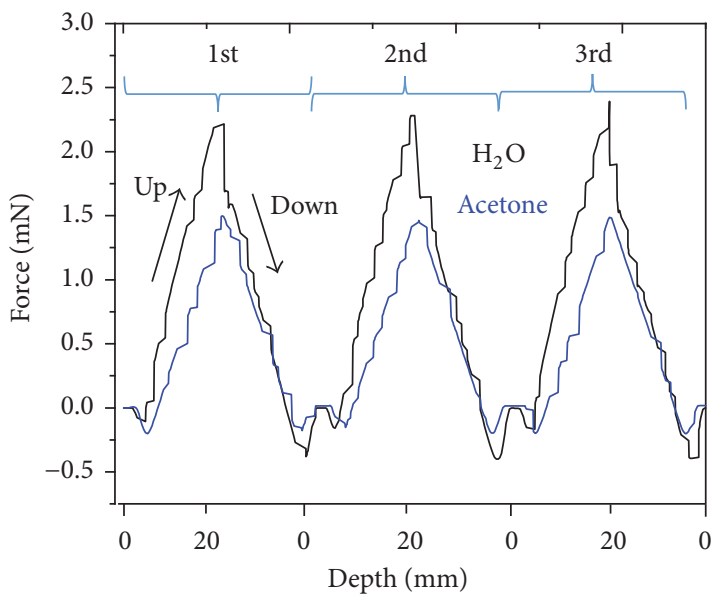

(c)

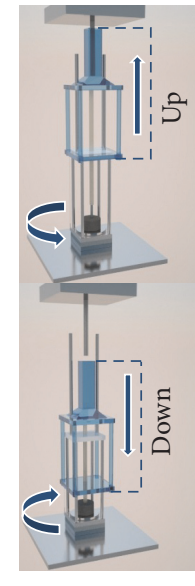

(d)

FIGURE 2: (a) Instinctive hardness test; (b) sketch of the device; (c) penetration force for water and acetone; (d) scanning setup.

each iron micro particle is surrounded by a "cloud" of magnetite nanoparticles (inset picture).

\subsection{Rheological Properties. The rheological properties of the} MR \# fluids were determined in a Paar-Physica MCR-300 (Austria) magneto rheometer using a plate-plate configuration $20 \mathrm{~mm}$ in diameter, with a $0.35 \mathrm{~mm}$ gap. The maximum applied field was $B=431 \mathrm{~m} \mathrm{~T}$. All measurements were taken at $25.0 \pm 0.2^{\circ} \mathrm{C}$.

2.3. Redispersibility. The method is based on recording the stiffness of the sediment by using a penetration standard needle connected to a digital semimicro balance (Mettler AE163, Switzerland) with a precision of $0.1 \mathrm{mg}\left(9.8 \times 10^{-4} \mathrm{mN}\right.$ weight). The velocity of the penetration was fixed at a constant value of $10 \mathrm{~mm} / \mathrm{s}$. Figure 2(a) shows the instinctive manual method to determine if the "cake" is hard or soft after sedimentation and the proposed device is shown in Figure 2(b). A stepper motor $\left(1.8^{\circ} /\right.$ step) is placed in the bottom of the device in order to drive a free vertical screw of the double decked platform located above it and is separated $80 \mathrm{~mm}$ from each layer to create enough space for the guide columns, to maintain the platform in horizontal alignment, and constitutes the mobile part of the mechanism, whose main objective is to displace vertically and uniformly the test tube crowning the device, towards a needle fixed to a scale, which is connected to a computer.

The scanning test consists of recording the mass displaced by the needle while the test tube moves vertically towards it, as shown in Figure 2(d). The sensitivity of the method is illustrated in Figure 2(c) where the penetration force is plotted as a function of the penetrated distance in water and in acetone. Note that the device can detect the immersion in both liquids, by manifestation of the buoyancy of the needle.
It should be noted that the sample tube is a removable container and does not constitute part of the device configuration, allowing independent storage and therefore the capability of analyzing samples with sedimentation-periods, lasting as long as the study warrants. With this setup, the device allows performing many penetration cycles in order to study the redispersibility of the suspensions under test.

From Figure 2(c) we can estimate the relation between the forces as a function of the penetration depth by a linear fitting of the first penetration step $(20 \mathrm{~mm}$ depth). In the sample with water this value is $0.052 \pm 0.003 \mathrm{mN} / \mathrm{mm}$, while in the acetone sample is $0.038 \pm 0.002 \mathrm{mN} / \mathrm{mm}$. Furthermore, we can distinguish the different peak force value needed to penetrate each liquid $(1.52 \mathrm{mN}$ for acetone and $2.25 \mathrm{mN}$ for water sample).

Redispersibility test for all samples was evaluated allowing MRF formulations to settle in test tubes for all samples: just prepared and after 10 and 30 days of storage.

\section{Results and Discussion}

3.1. Magnetorheological Test. The magnetorheological characterization of the suspensions was carried out by obtaining the shear stress versus shear rate in a wide range of applied magnetic field. Figure 3(a) shows the steady state rheograms (shear stress versus shear rate) obtained for MRF \#1, MRF \#2, and MRF \#3 for different magnetic field applied.

In all the cases of samples MRF \#1, MRF \#2, and MRF \#3 the magnetorheological behavior is similar. The lower value of shear stress in the sample MRF \#1 compared to the others is due to the absence of any additives, while the value of MRF \#2 and MRF \#3 without magnetic field is nearly double as a consequence of the increase of the viscosity of the carrier in both cases. Furthermore, the maximum value achieved with a magnetic field strength of $430 \mathrm{mT}$ is more or less similar in all of them, with a small difference in the case of the 

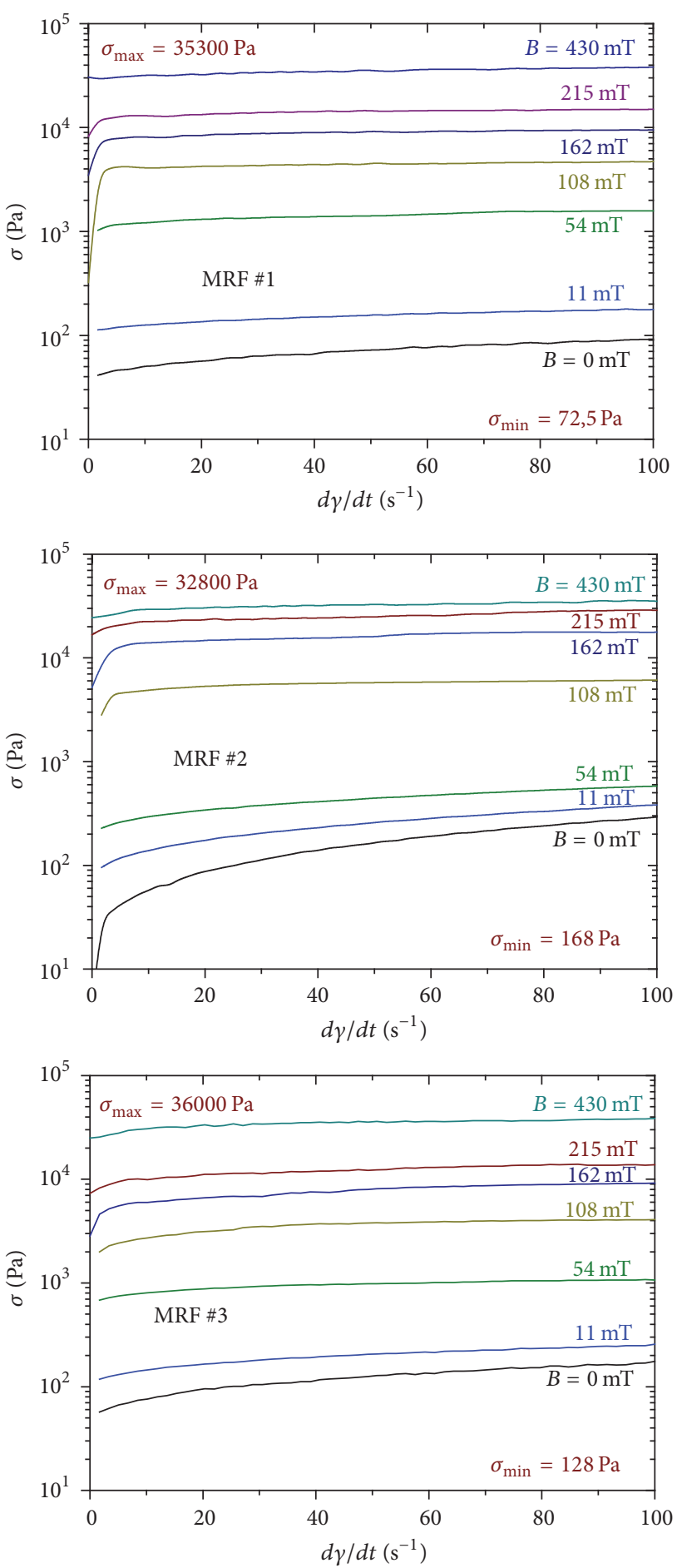

(a)

\begin{tabular}{lr}
\multicolumn{3}{c}{ MRF \#1 } \\
\hline$\sigma_{\min }(\mathrm{Pa})$ & $\sigma_{\max }(\mathrm{Pa})$ \\
\hline 72,5 & 35300 \\
\hline
\end{tabular}

MRF \#2

\begin{tabular}{lc}
\hline$\sigma_{\min }(\mathrm{Pa})$ & $\sigma_{\max }(\mathrm{Pa})$ \\
\hline 168 & 32800 \\
\hline
\end{tabular}

\begin{tabular}{lc}
\multicolumn{3}{c}{$\mathrm{MRF} \# 3$} \\
\hline$\sigma_{\min }(\mathrm{Pa})$ & $\sigma_{\max }(\mathrm{Pa})$ \\
\hline 128 & 36000 \\
\hline
\end{tabular}

(b)

FIGURE 3: (a) Steady state rheograms (shear stress versus shear rate) for all samples. (b) Shear rate values (min. and max.) into the postyield region (shear rate $>30 \mathrm{~s}^{-1}$ ).

addition of nanoparticles, as López-López et al. [14] found that the yield stress increased significantly, if sufficiently concentrated ferrofluids were used as carriers in MRFs. Also, this small increase of the MR effect in sample MRF \#3 could be explained due to the formation of a protective "halo" of magnetite nanoparticles around the iron micro particles shown in Figure 1(c). This structure prevents the particles from aggregation and maximizing the MR response. 


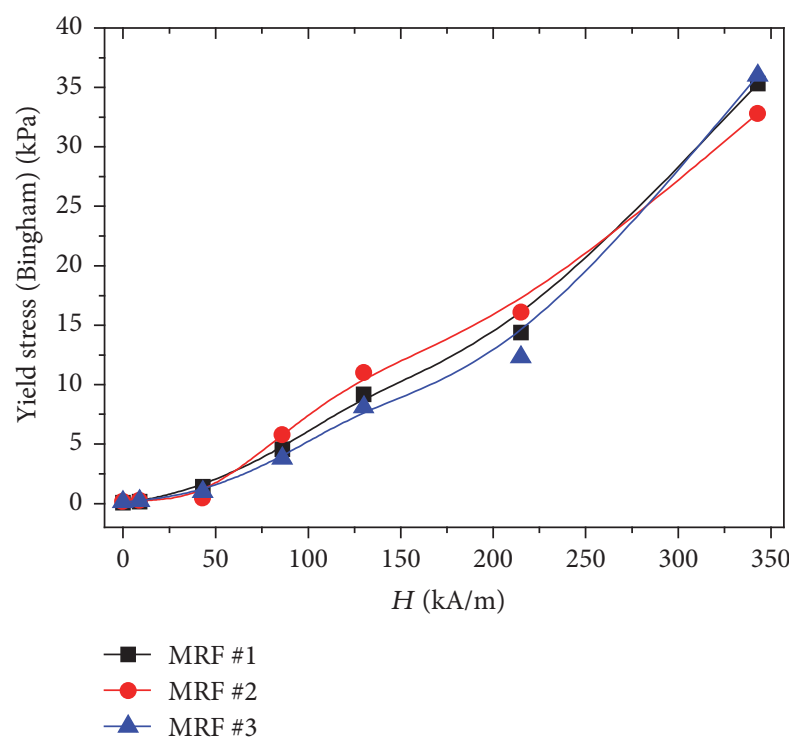

(a)

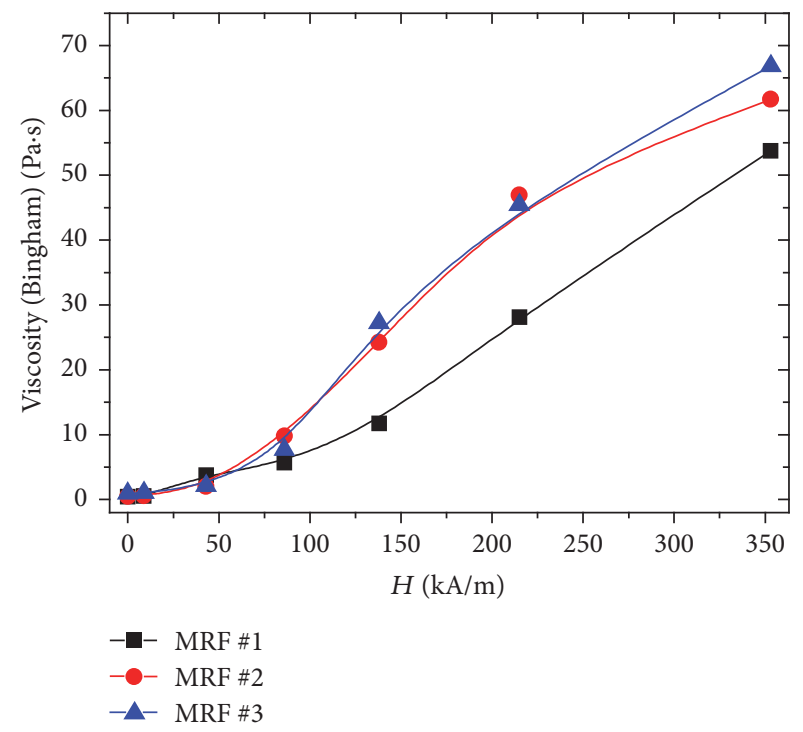

(b)

FIGURE 4: (a) Dynamic yield stress and (b) shear viscosity as a function of magnetic field strength.

The dynamic yield stress $\left(\sigma_{y}\right)$ and the viscosity $\left(\eta_{B}\right)$ for MRF \#1, MRF \#2, and MRF \#3 suspensions were estimated by fitting the shear stress $(\sigma)$ versus the shear rate $(d \gamma / d t)$ data from Figure 3 to the Bingham plastic model $\sigma=\sigma_{y}+\eta_{B} d \gamma / d t$. These fits were performed for shear rate values well into the postyield region $\left(d \gamma / d t>30 \mathrm{~s}^{-1}\right)$. As observed in Figures 4(a) and 4(b), the application of a magnetic field provokes a nonNewtonian plastic behavior. Figure 4(a) indicates a similar MR effect in all suspension. From a rheological point of view, it seems that the advantage of the MRF \#3 with nanoparticles over the others MRFs is the wider range of field-controlled viscosity variation (Figure $4(\mathrm{~b})$ ).

3.2. Redispersibility. Sedimentation is an inevitable consequence of the two components of MR fluid. It has a liquid carrier like oils or water and a solid part composed of iron, nickel, or other metallic particles as well. Longer periods of sedimentation lead inevitably to the formation of sediment and in consequence to nonoperating of the MR fluid. The key of the design MR fluid is then to use conditions such that the mechanical hardness of this sediment is not as high as to produce an easy redispersion upon gentle shaking.

Figure 5 shows the redispersion experiment of the samples. These experiments were performed during 30 days of storage with one measure on day ten. As we can see in the figure for just prepared samples, the penetration test was similar in all of them. The initial slope and the force peak are nearly the same for all the samples, but this behavior was not quite what we could predict after 10 and 30 days.

In MRF \#1 and MRF \#3 the increase of the force peak since 30 days of storage was about three times the initial value and this was similar in the third penetration step. In the MRF \#2 the behavior was different. The slope value of MRF \#2 after 10 days of storage was lower than the other fluids, but at the end of the test (day 30 ), the value was seven times higher than the first penetration step and decreases with the subsequence step to a similar value of MRF \#1 thanks to the addition of the additives. Furthermore, in MRF \#1 the peak force increases $10 \%$ and in MRF \#3 decreases $10 \%$ of the initial value after three penetrations after 30 days of storage.

It is important to remark that the samples without nanoparticles offer a larger penetration resistance near the end of the run, clear evidence of the finding of hard, compact sediment. On the contrary, the samples prepared with nanoparticles are characterized by a slight monotonous increase all along their height but remain small after 10 and 30 days. This MRF \#3 shows minimum penetration force and it could be confirming that the halo of nanoparticles keeps the iron microspheres away from each other, preventing their irreversible aggregation by either van der Waals or magnetic attraction.

\section{Conclusions}

The addition of nanoparticles as a carrier indicated that it could be enhancing the magnetorheological behavior of the MR fluid compared to the fluid containing stabilizing and thickening compounds additives. Another remarkable difference of the MR fluid with nanoparticles is the larger magnetic field-induced variation in the viscosity compared with the other fluids under study.

The method based on the evaluation of the hardness of the sediment by measuring the force of penetration of a standard needle led us to the conclusion that the use of nanoparticles as a carrier liquid in our formulation avoids the formation of compact sediments during long shelf or storage periods. A volume fraction of nanoparticles of $6.2 \% \mathrm{v} / \mathrm{v}$ was evaluated and was enough to achieve such easy redispersion. The benefit on the redispersibility of the fluid could come from the protecting effect of nanoparticles surrounding the iron micro 


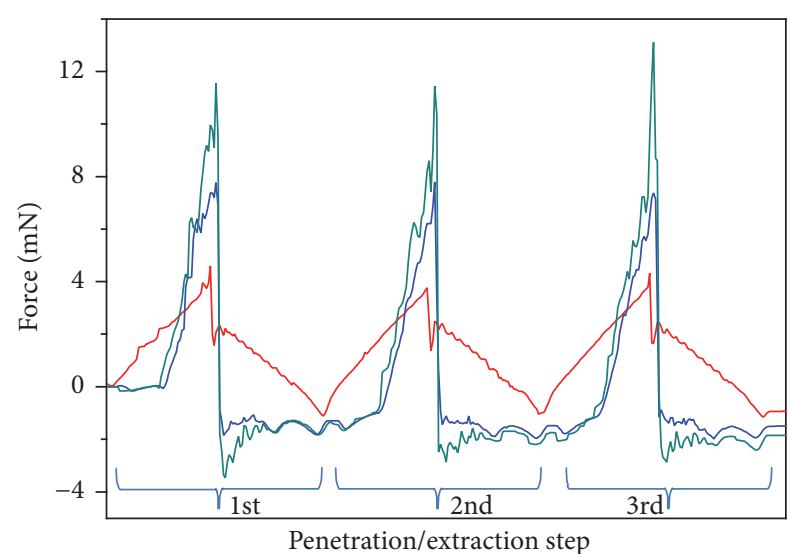

\begin{tabular}{lccccc} 
& MR \#1 & & & \\
\hline Rest (days) & $\begin{array}{c}\text { Slope } \\
(\mathrm{mN} / \mathrm{mm})\end{array}$ & & \multicolumn{4}{c}{ Force peak $(\mathrm{mN})$} \\
\hline 0 & 0.075 & 4.61 & 3,76 & 4,31 \\
10 & 0.316 & 7.77 & 7,80 & 7,40 \\
30 & 0.370 & & 11.54 & 11,44 & 13,11 \\
\hline
\end{tabular}

MR \#1

— Just prepared

- 10 days' rest

30 days' rest

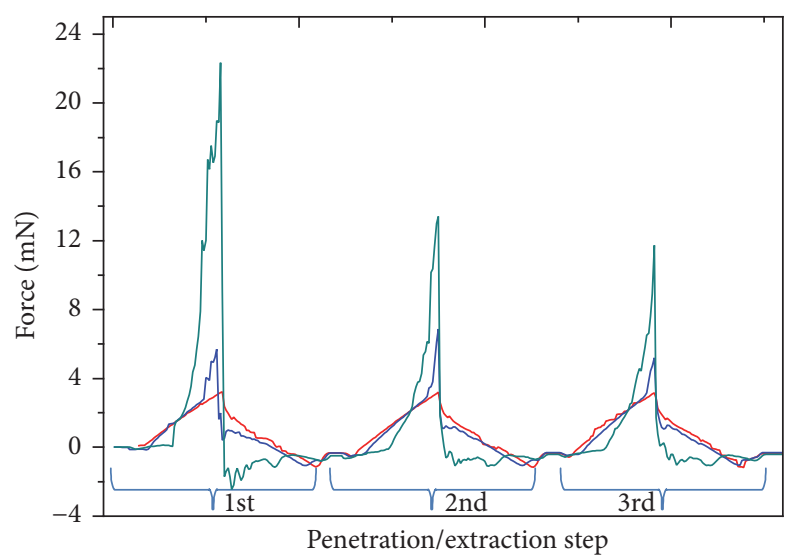

\begin{tabular}{lccccc} 
& MR \#2 & & & \\
\hline Rest (days) & $\begin{array}{c}\text { Slope } \\
(\mathrm{mN} / \mathrm{mm})\end{array}$ & \multicolumn{4}{c}{ Force peak $(\mathrm{mN})$} \\
\hline 0 & 0.070 & 3.23 & 3,20 & 3,17 \\
10 & 0.130 & 5.71 & 6,88 & 5,20 \\
30 & 0.861 & 22.34 & 13,41 & 11,73 \\
\hline
\end{tabular}

MR \#2

_ Just prepared

- 10 days' rest

_ 30 days' rest

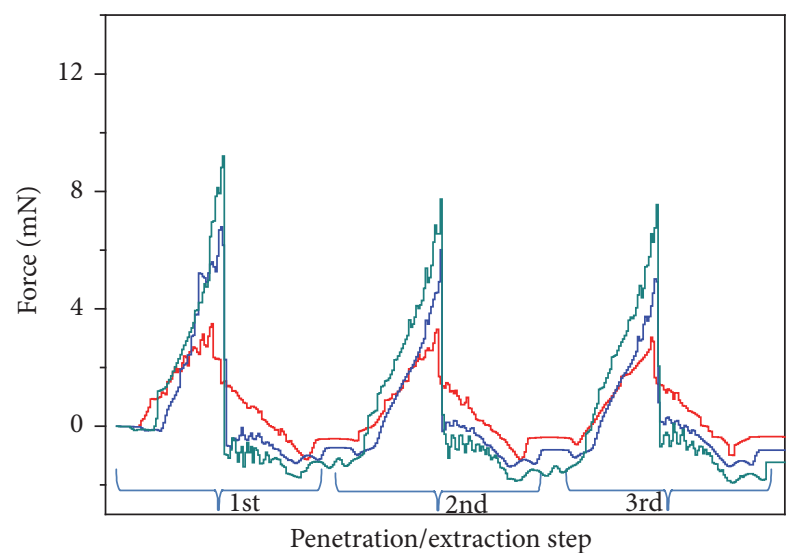

\begin{tabular}{lccccc}
\multicolumn{3}{c}{ MR\#3 } \\
\hline Rest (days) & $\begin{array}{c}\text { Slope } \\
(\mathrm{mN} / \mathrm{mm})\end{array}$ & \multicolumn{4}{c}{ Force peak $(\mathrm{mN})$} \\
\hline 0 & 0.080 & 3.49 & 3,31 & 3,04 \\
10 & 0.217 & 6.79 & 6,01 & 5,02 \\
30 & 0.215 & 9.21 & 7,74 & 7,54 \\
\hline
\end{tabular}

MR \#3

$$
\begin{aligned}
& \text { - Just prepared } \\
& -10 \text { days' rest } \\
& -30 \text { days' rest }
\end{aligned}
$$

(a)

(b)

FIGURE 5: (a) Force versus penetration step for all MRFs. (b) Slope and peak force value of 0, 10, and 30 days after storage. 
particles and avoiding short-range attractions between them, thus hindering the occurrence of compact sediments.

\section{Conflicts of Interest}

The authors declare that there are no conflicts of interest regarding the publication of this paper.

\section{Acknowledgments}

The authors acknowledge the financial support from Spanish Government: RYC-2014-16901 (MINECO), FIS2013-07666C3-1-R (Ministerio de Ciencia e Innovación, Spain), and PE2012-FQM-0694 (Junta de Andalucía, Spain).

\section{References}

[1] M. Zubieta, S. Eceolaza, M. J. Elejabarrieta, and M. M. Bou-Ali, "Magnetorheological fluids: Characterization and modeling of magnetization," Smart Materials and Structures, vol. 18, no. 9, Article ID 095019, 2009.

[2] E. M. Furst and A. P. Gast, "Micromechanics of magnetorheological suspensions," Physical Review E - Statistical Physics, Plasmas, Fluids, and Related Interdisciplinary Topics, vol. 61, no. 6 B, pp. 6732-6739, 2000.

[3] M. Ashtiani, S. H. Hashemabadi, and A. Ghaffari, "A review on the magnetorheological fluid preparation and stabilization," Journal of Magnetism and Magnetic Materials, vol. 374, pp. 716730, 2015.

[4] M. Ashtiani and S. H. Hashemabadi, "An experimental study on the effect of fatty acid chain length on the magnetorheological fluid stabilization and rheological properties," Colloids and Surfaces A: Physicochemical and Engineering Aspects, vol. 469, pp. 29-35, 2015.

[5] M. T. López-López, G. Vertelov, G. Bossis, P. Kuzhir, and J. D. G. Durán, "New magnetorheological fluids based on magnetic fibers," Journal of Materials Chemistry, vol. 17, no. 36, pp. 38393844, 2007.

[6] R. V. Upadhyay, Z. Laherisheth, and K. Shah, "Rheological properties of soft magnetic flake shaped iron particle based magnetorheological fluid in dynamic mode," Smart Materials and Structures, vol. 23, no. 1, Article ID 015002, 2014.

[7] J. de Vicente, D. J. Klingenberg, and R. Hidalgo-Alvarez, "Magnetorheological fluids: a review," Soft Matter, vol. 7, no. 8, pp. 3701-3710, 2011.

[8] B. J. Park, F. F. Fang, and H. J. Choi, "Magnetorheology: materials and application," Soft Matter, vol. 6, no. 21, pp. 5246-5253, 2010.

[9] S. Genç and P. P. Phulé, "Rheological properties of magnetorheological fluids," Smart Materials \& Structures, vol. 11, no. 1, pp. 140-146, 2002.

[10] G. R. Lglesias, S. Ahualli, J. Echávarri Otero, L. F. Ruiz-Morón, and J. D. G. Durán, “Theoretical and experimental evaluation of the flow behavior of a magnetorheological damper using an extremely bimodal magnetic fluid," Smart Materials and Structures, vol. 23, no. 8, Article ID 085028, 2014.

[11] A. Q. Bhatti, "Performance of viscoelastic dampers (VED) under various temperatures and application of magnetorheological dampers (MRD) for seismic control of structures," Mechanics of Time-Dependent Materials, vol. 17, no. 3, pp. 275284, 2013.
[12] S. H. Eem, H. J. Jung, and J. H. Koo, "Seismic performance evaluation of an MR elastomer-based smart base isolation system using real-time hybrid simulation," Smart Materials and Structures, vol. 22, no. 5, Article ID 055003, 2013.

[13] F. Gordaninejad, X. Wang, G. Hitchcock, K. Bangrakulur, S. Ruan, and M. Siino, "Modular high-force seismic magnetorheological fluid damper," Journal of Structural Engineering, vol. 136, no. 2, pp. 135-143, 2010.

[14] M. T. López-López, P. Kuzhir, S. Lacis, G. Bossis, F. GonzálezCaballero, and J. D. G. Durán, "Magnetorheology for suspensions of solid particles dispersed in ferrofluids," Journal of Physics Condensed Matter, vol. 18, no. 38, article no. S18, pp. S2803-S2813, 2006.

[15] C. Rossa, A. Jaegy, J. Lozada, and A. Micaelli, "Design considerations for magnetorheological brakes," IEEE/ASME Transactions on Mechatronics, vol. 19, no. 5, pp. 1669-1680, 2014.

[16] G. T. Ngatu and N. M. Wereley, "Viscometric and sedimentation characterization of bidisperse magnetorheological fluids," IEEE Transactions on Magnetics, vol. 43, no. 6, pp. 2474-2476, 2007.

[17] J. Yang, H. Yan, Z. Hu, and D. Ding, "Viscosity and sedimentation behaviors of the magnetorheological suspensions with oleic acid/dimer acid as surfactants," Journal of Magnetism and Magnetic Materials, vol. 417, pp. 214-221, 2016.

[18] K. Shah and S.-B. Choi, "The influence of particle size on the rheological properties of plate-like iron particle based magnetorheological fluids," Smart Materials and Structures, vol. 24, no. 1, Article ID 015004, 2015.

[19] K. Shah and S.-B. Choi, "Rheological properties of magnetorheological polishing fluid featuring plate-like iron particles," Smart Materials and Structures, vol. 23, no. 11, Article ID 117003, 2014.

[20] K. Shah, J.-S. Oh, S.-B. Choi, and R. V. Upadhyay, "Plate-like iron particles based bidisperse magnetorheological fluid," Journal of Applied Physics, vol. 114, no. 21, Article ID 213904, 2013.

[21] A. Fuchs, M. Xin, F. Gordaninejad et al., "Development and Characterization of Hydrocarbon Polyol Polyurethane and Silicone Magnetorheological Polymeric Gels," Journal of Applied Polymer Science, vol. 92, no. 2, pp. 1176-1182, 2004.

[22] T. Liu, X. Gong, Y. Xu, S. Xuan, and W. Jiang, "Simulation of magneto-induced rearrangeable microstructures of magnetorheological plastomers," Soft Matter, vol. 9, no. 42, pp. 10069 10080, 2013.

[23] J. De Vicente, M. T. López-López, F. González-Caballero, and J. D. G. Durán, "Rheological study of the stabilization of magnetizable colloidal suspensions by addition of silica nanoparticles," Journal of Rheology, vol. 47, no. 5, pp. 1093-1109, 2003.

[24] M. T. López-López, A. Gómez-Ramírez, J. D. G. Durán, and F. González-Caballero, "Preparation and characterization of iron-based magnetorheological fluids stabilized by addition of organoclay particles," Langmuir, vol. 24, no. 14, pp. 7076-7084, 2008.

[25] M. T. López-López, A. Zugaldia, A. Gómez-Ramirez, F. González-Caballero, and J. D. G. Durán, "Effect of particle aggregation on the magnetic and magnetorheological properties of magnetic suspensions," Journal of Rheology, vol. 52, no. 4, pp. 901912, 2008.

[26] G. A. van Ewijk and A. P. Philipse, "Anomalous attraction between colloidal magnetite and silica spheres in apolar solvents," Langmuir, vol. 17, no. 23, pp. 7204-7209, 2001.

[27] O. Volkova, G. Bossis, M. Guyot, V. Bashtovoi, and A. Reks, "Magnetorheology of magnetic holes compared to magnetic particles," Journal of Rheology, vol. 44, no. 1, pp. 91-104, 2000. 
[28] J. H. Park, B. D. Chin, and O. O. Park, "Rheological properties and stabilization of magnetorheological fluids in a water-in-oil emulsion," Journal of Colloid and Interface Science, vol. 240, no. 1, pp. 349-354, 2001.

[29] P. J. Rankin, J. M. Ginder, and D. J. Klingenberg, "Electroand magneto-rheology," Current Opinion in Colloid \& Interface Science, vol. 3, no. 4, pp. 373-381, 1998.

[30] M. T. López-López, A. Zugaldía, F. González-Caballero, and J. D. G. Durán, "Sedimentation and redispersion phenomena in iron-based magnetorheological fluids," Journal of Rheology, vol. 50, no. 4, pp. 543-560, 2006.

[31] P. P. Phulé, M. P. Mihalcin, and S. Genc, "Role of the dispersedphase remnant magnetization on the redispersibility of magnetorheological fluids," Journal of Materials Research, vol. 14, no. 7, pp. 3037-3041, 1999.

[32] M. Mrlík, M. Ilčíková, V. Pavlínek, J. Mosnáček, P. Peer, and P. Filip, "Improved thermooxidation and sedimentation stability of covalently-coated carbonyl iron particles with cholesteryl groups and their influence on magnetorheology," Journal of Colloid and Interface Science, vol. 396, pp. 146-151, 2013.

[33] G. R. Iglesias, M. T. López-López, J. D. G. Durán, F. GonzálezCaballero, and A. V. Delgado, "Dynamic characterization of extremely bidisperse magnetorheological fluids," Journal of Colloid and Interface Science, vol. 377, no. 1, pp. 153-159, 2012.

[34] A. J. Bombard, L. S. Antunes, P. P. P. Balestrassi, and A. P. Paiva, "Magneto-rheological fluids redispersibility - a factorial design study of phosphate shell on carbonyl iron powder with dispersing additives," Journal of Physics: Conference Series, vol. 149, 11th Conference on Eletrotheological Fluids and Magnetorheological Suspensions, no. 1, pp. 1-5, 2009.

[35] A. Fuchs, A. Rashid, Y. Liu, B. Kavlicoglu, H. Sahin, and F. Gordaninejad, "Compressible magnetorheological fluids," Journal of Applied Polymer Science, vol. 115, no. 6, pp. 3348-3356, 2010.

[36] I. Pramudya, J. Sutrisno, A. Fuchs, B. Kavlicoglu, H. Sahin, and F. Gordaninejad, "Compressible magnetorheological fluids based on composite polyurethane microspheres," Macromolecular Materials and Engineering, vol. 298, no. 8, pp. 888-895, 2013.

[37] M. T. López-López, J. D. G. Durán, A. V. Delgado, and F. González-Caballero, "Stability and magnetic characterization of oleate-covered magnetite ferrofluids in different nonpolar carriers," Journal of Colloid and Interface Science, vol. 291, no. 1, pp. 144-151, 2005. 

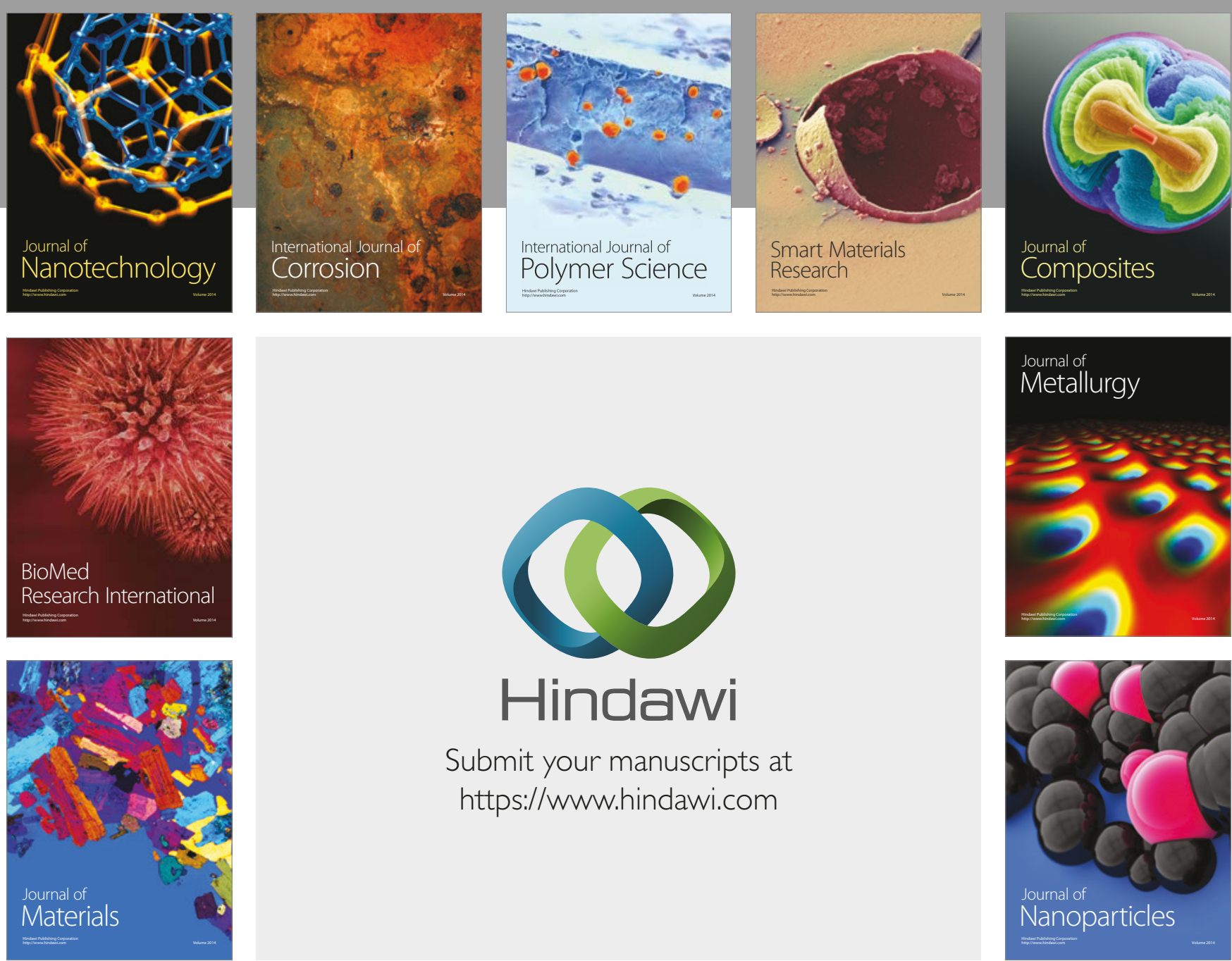

\section{Hindawi}

Submit your manuscripts at

https://www.hindawi.com
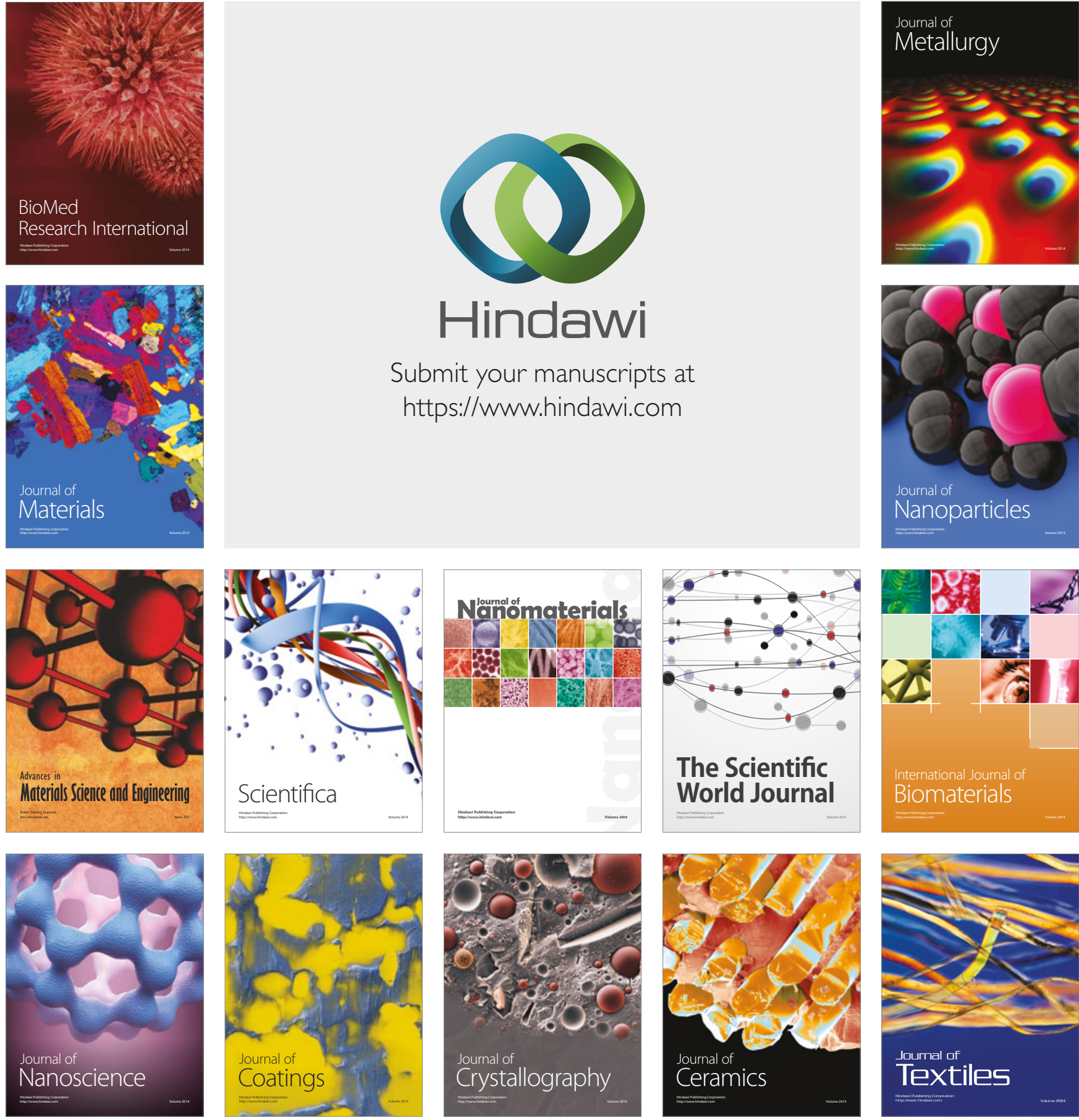

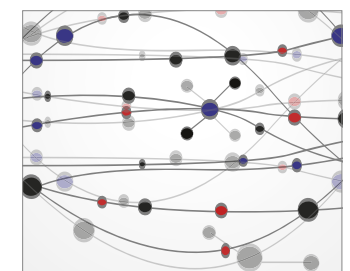

The Scientific World Journal
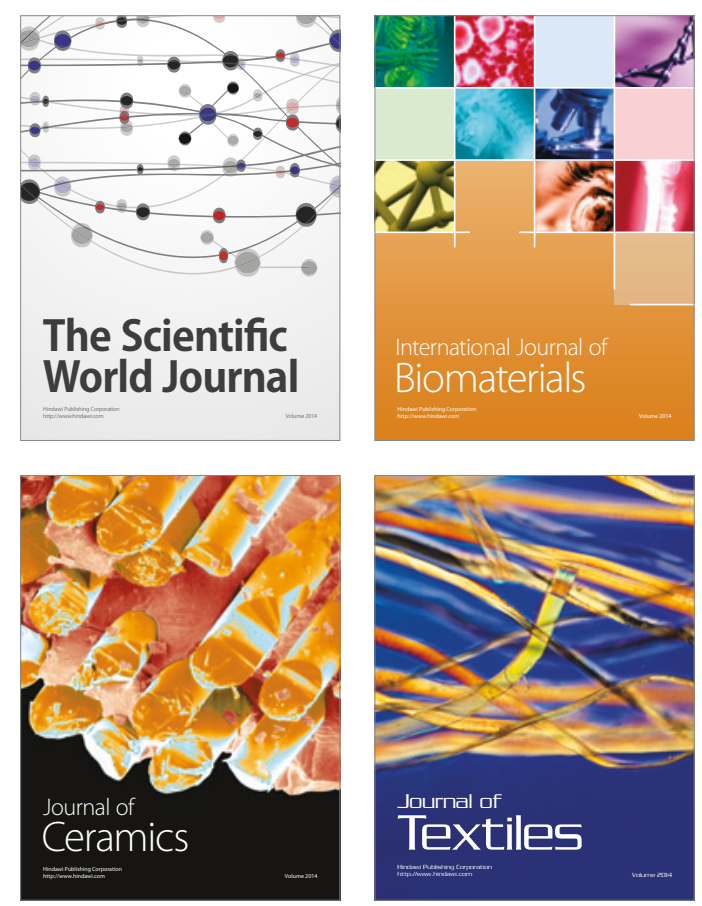